\title{
Phytochemical Screening of Polipog Decoction
}

\author{
Aljon Victor G. Nibalvos \\ College of Arts and Sciences, Eastern Samar State University, Borongan City, Philippines; \\ aljonvictorgalitnibalvos@gmail.com
}

\begin{abstract}
Objectives: This study centralizes on determining the present secondary metabolites in the decoctions of polipog which is commonly used in Borongan City for various ailments and for its medicinal value. Methods: This study used qualitative analysis under the experimental research design to elaborate the physical properties of the Ligustrum sp. decoction together with its present phytochemicals, all under laboratory conditions. Results: It was found out that in terms of its physical properties, the polipog decoction has the color of brown, has a soya curd-like odor, a pH of 5.0 which means that the substance is acidic and a polar nature because of its dissolving property to alcohol, diluted $\mathrm{HCl}$ and diluted $\mathrm{NaOH}$. Lastly, of all the nine (9) metabolites, six (6) were found to be present in the decoction which follows namely; flavonoids, phenolic compounds, phytosterols, proteins, saponins and tannins. However, alkaloid, carbohydrates and glycosides were absent from the said decoction. This implies that polipog decoction contains numerous amounts of phytochemicals which can be used for their medicinal or pharmaceutical importance. Improvements: It is therefore recommended that an isolation and further identification study be conducted to determine the structure of the present secondary metabolites found in the polipog decoction.
\end{abstract}

Keywords: Decoction, Medicinal Value, Phytochemical Screening, Polipog, Secondary Metabolites

\section{Introduction}

Many medicines that are now being used in the market come from plant-derived substances or what we call phytochemicals. These diverse chemical substances 1 are first identified by phytochemical screening. Phytochemical screening is a qualitative to semi-quantitative analysis of plant extracts coming from different plant parts. These secondary metabolites when subjected to analysis can be used for various purposes such as curing illnesses, vitamin source or even for cooking and culinary purposes.

Plant secondary metabolites are compounds produced by plants 2 during their metabolism other than photosynthesis. This process produces diverse amounts of specialized compounds which do not aid in the growth and development of the plant itself, but needs these compounds for survival in different environment. Hence, most plants have different concentrations and presence of secondary metabolites when grown in a different environment.

One major plant that is a center of attraction to the researcher is the polipog, or only scientifically known as "Ligustrum sp." This tree can be seen in forests and is usually sold in the Borongan Public Market. The polipog has a high demand for it is typically used by newly delivered mothers to aid in getting back the vigor and health of their body. Also, some say that it can be used to cure certain illnesses and even cancer just by drinking its decoction. This information prompted the researcher to grow interest on the plant and determine its chemical characteristics and its phytochemical components.

\subsection{Objectives of the Study}

This study was conducted to determine the present secondary metabolites in Polipog decoction. More specifically, this study tried to: 
- Determine the physical properties of the polipog decoction in terms of:
* Color
* Odor
* $\mathrm{pH}$
* Solubility

- Determine the secondary metabolites of polipog decoction in terms of:

* Alkaloids

* Carbohydrates

* Flavonoids

* Glycosides

* Phenolic compounds

* Phytosterols/Triterpenes

* Proteins/Amino acids

* Saponins

* Tannins

\section{Methodology}

\subsection{Research Design}

This study made use of the Experimental Research Design using Qualitative Analysis to determine the physical properties and the present secondary metabolites in the decoction of polipog stem. This was Qualitative analysistype of research which means that this study will only identify the present phytochemicals but will not provide numerical data. All tests will be done in three (3) trials for a more firm data.

\subsection{Locale of the Study}

This experimental study was done at the Chemistry Laboratory, Science Complex, College of Arts and Sciences, Eastern Samar State University, Borongan City, Eastern Samar Polipog samples were collected from the Public Market of Borongan City, Eastern Samar.

\subsection{Data Gathering Procedures}

The following sets of procedures were utilized to maintain a reproducible result of this study. The decoction of the sample was evaluated at the liquid state, implying that there are traces of impurities during the decoction process.

\subsection{Collection and Preparation of Ligustrum sp. Sample}

Dried braches and stems of the polipog tree were gathered at the Public Market of Borongan City, Eastern Samar. 300 grams of dried polipog stem were collected. The said samples was then brought into the Chemistry Laboratory which was subjected to distilled water to clear out unwanted particulates. After cleaning decoction process followed immediately. This was done by immersing the 300 grams of coarsely cut polipog samples to 1.5 liter of distilled water. It was then boiled in a hot plate for 30 minutes; evaporated water was replaced by adding enough water into the decoction until the time mark.

After the mark, the solid particulates of the polipog was expelled out from the remaining liquid part and concentrated to $500 \mathrm{~mL}$. The remaining concentrate was then filtered, cooled and transferred into a clean reagent bottle, and this was now used for determining its physical properties and the presence of secondary metabolites.

\subsection{Physical Properties Determination}

The following procedures were utilized to the polipog decoction to determine its physical properties.

\section{Color}

The color of the decoction was assessed by five (5) random respondents by their sense of sight. The perceived color of the respondents was recorded.

\section{Solubility}

Solubility is the property of a solid substance to mix in a given solvent. In this test, four (4) solvents namely; alcohol, benzene, $10 \% \mathrm{HCl}, 10 \% \mathrm{NaOH}$ was used as solvents to determine the solubility of the decoction. About $1 \mathrm{~mL}$ equivalent of sample was added to $4 \mathrm{~mL}$ of solvent. Then, it was observed and the results were recorded. Three trials were done on each solvent.

\section{Odor}

The odor of the polipog decoction was assessed by five (5) random respondents by their olfactory sense. The perceived odor of the respondents was recorded. 


\section{$p H$}

The $\mathrm{pH}$ of the sample extracts will be determined by using a $\mathrm{pH}$ paper. The paper was dipped into the polipog decoction and the reading of the $\mathrm{pH}$ paper was analyzed using a $\mathrm{pH}$ indicator and it was recorded.

\section{Phytochemical Screening}

The following procedures were utilized to the polipog decoction in three (3) trials to determine the present secondary metabolites. Procedures were taken from Guevara, BQ. (2004) "A Guidebook to Plant Screening: Phytochemical and Biological"3 and "Phytochemical Screening and Extraction: A Review"1.

\section{Alkaloids}

$5 \mathrm{~mL}$ of decoction was dissolved in $10 \% \mathrm{HCl}$ solution and filtered. The filtrate was then subjected to alkaloid testing using Wagner's Test. In this test, the filtrate was treated with Wagner's solution (Iodine in KI solution). The formation of a brown/reddish precipitate indicates the presence of alkaloids.

\section{Carbohydrates}

$5 \mathrm{~g}$ equivalent of polipog decoction was dissolved in 5 $\mathrm{mL}$ of distilled water and then filtered. The filtrate was then used to test for the presence of carbohydrates using Benedict's Test.

The filtrate was treated with Benedict's reagent and heated gently over a water bath for 10 minutes. Appearance of orange - red precipitate indicates the presence of reducing sugars.

\section{Glycosides}

A total of $5 \mathrm{~mL}$ polipog decoction was hydrolyzed with 5\% hydrochloric acid and then subjected to Modified Borntrager's Test for anthranol glycosides.

The hydrolyzed decoction was treated with $5 \% \mathrm{FeCl}_{3}$ solution and then immersed in water bath for 5 minutes. The mixture was cooled and then extracted with equal volumes of benzene. The benzene layer was separated and treated with $25 \%$ ammonia solution. The formation of rose-pink color in the ammoniacal layer indicates the presence of anthranol glycosides.

\section{Saponins}

Froth test was used to determine the presence of saponins in the polipog decoction. $5 \mathrm{~mL}$ sample was used. The sample decoction was diluted with distilled water to 20 $\mathrm{mL}$ and shaken for 15 minutes. The formation of $1 \mathrm{~cm}$ layer of foam indicates the presence of saponins.

\section{Phytosterols}

Using Salkowski's Test, the presence of triterpenes was determined in a $5 \mathrm{~mL}$ sample of polipog decoction. The decoction was treated with $\mathrm{CHCl}_{3}$ and filtered. The filtrate was then added with 5 drops of concentrated $\mathrm{H}_{2} \mathrm{SO}_{4}$, shaken and allowed to stand for 30 minutes. Appearance of golden yellow color indicates the presence of triterpenes.

\section{Phenolic Compounds}

Ferric chloride Test was used to determine the presence of compounds that contain phenol molecules. The polipog decoction having a volume of $5 \mathrm{~mL}$ was treated with 3-4 drops of $\mathrm{FeCl}_{3}$ solution. Immediate appearance of a bluish black color indicates the presence of phenols.

\section{Flavonoids}

Using Alkaline Reagent Test, $5 \mathrm{~mL}$ of polipog decoction was verified for the presence of flavonoid. The decoction was treated with 3-5 drops of $2 \mathrm{M} \mathrm{NaOH}$ solution. The formation of an intense yellow color, which becomes colorless on addition of dilutes $\mathrm{HCl}$ indicates the presence of flavonoids.

\section{Proteins}

Xanthoproteic Test was used to determine the presence of proteins in a $5 \mathrm{~mL}$ sample of polipog solution. The decoctions were treated with 5 drops of concentrated $\mathrm{HNO}_{3}$ solution. The formation of a yellow color indicates the presence of proteins and amino acids.

\section{Tannins}

Gelatin Test was used to determine the presence of tannins in a $5 \mathrm{~mL}$ of decoction sample. To the sample, 10 drops of $1 \%$ gelatin-salt reagent was added. The formation of a white precipitate indicates the presence of tannins. 
All results in the physical and phytochemical analyses were recorded.

\section{Results and Discussion}

After thorough experimentation, the following results were obtained: It was found out that, of all nine (9) secondary metabolites, six (6) were found to be present in the decoction of polipog. This implies that polipog decoction contains numerous number of phytochemical which can be further utilized for its medicinal and therapeutic value in medicine and pharmacology. These secondary metabolites give evidence on the medical and beneficial effect of polipog decoction used by Estehanons. The results can be further seen in the Table 1 .

\section{Conclusions}

Based on the results of the study, the researcher concludes the following:

- The color of the polipog decoction is brown, with a soya curd-like odor, an acidic $\mathrm{pH}$ value and solubility to polar solvents.
- Six (6) secondary metabolites were found to be present in the polipog decoction namely; flavonoids, phenolic compounds, phytosterols, proteins, saponins and tannins all of which has its specific medicinal and pharmaceutical significance.

- Other important secondary metabolites were found to be lacking in the decoction of the polipog and they are; alkaloid, carbohydrates and glycosides.

- The present secondary metabolites are evidence of the herbal and neutraceutical value of the polipog plant.

\section{Recommendations}

Based on the conclusions of the study, the following recommendations are herein enjoined to be pursued further by researchers:

- Conduct isolation and identification of the present secondary metabolites found in the polipog decoction.

Table 1. Phytochemical Screening of Polipog Decoction

\begin{tabular}{|c|c|c|}
\hline \multicolumn{3}{|l|}{ Physical Properties } \\
\hline & Observations & Interpretations \\
\hline Color & Brown & \\
\hline Odor & Soya curd-like odor & Pleasant \\
\hline $\mathrm{pH}$ & 5.0 & Acidic \\
\hline \multicolumn{3}{|l|}{ Solubility } \\
\hline Alcohol & Soluble & Decoction is polar in nature \\
\hline Benzene & Insoluble & Decoction is polar in nature \\
\hline $10 \% \mathrm{HCl}$ & Soluble & Decoction is polar in nature \\
\hline $10 \% \mathrm{NaOH}$ & Soluble & Decoction is polar in nature \\
\hline \multicolumn{3}{|l|}{ Secondary Metabolites } \\
\hline Alkaloids & No alkaloid present & Negative \\
\hline Carbohydrates & No carbohydrates present & Negative \\
\hline Flavonoids & Presence of Flavonoids & Positive \\
\hline Glycosides & Absence of Anthranol Glycosides & Negative \\
\hline Phenolic compounds & Presence of Phenolic Compounds & Positive \\
\hline Phytosterols & Presence of Phytosterols & Positive \\
\hline Proteins & Presence of Proteins & Positive \\
\hline Saponins & Presence of Saponins & Positive \\
\hline Tannins & Presence of Tannin & Positive \\
\hline
\end{tabular}


- Conduct similar study utilizing different solvents to maximize extraction of secondary metabolites.

- Conduct a similar study to further affirm or oppose the results of the current study.

- Conduct a bioassay study on the polipog decoction.

- Conduct phytochemical screening tests to other plants with medicinal importance found in Eastern Samar.

\section{References}

1. Tiwari P, Kumar B, Kaur M, Kaur G, Kaur H. Phytochemical Screening and Extraction: A Review. Internationale Pharmaceutica Sciencia. 2011; 1(1):98-106.

2. Kumar D, Kumar S, Singh J, Sharma C. Aneja KR. Antimicrobial and preliminary phytochemical screening of crude leaf extract of pandanus odoratissimus 1 . Pharmacology Online. 2010; (2):600-10.

3. Guevara BQ. A Guidebook to Plant Screening: Phytochemical and Biological. Revised Edition. University of Santo Tomas Publishing House: Manila. 2004; p. 1-19. PMid:15000763 